\title{
Peripheral Artery Disease as a Risk Factor for Myocardial Infarction
}

Erick Leonel Pérez Mejias ${ }^{1}$, Sila Mateo Faxas ${ }^{1}$, Nicole Tejeda Taveras ${ }^{2}$, Abdul Subhan Talpur ${ }^{3}$, Jitesh Kumar $^{4}$, Maria Khalid ${ }^{5}$, Suraj K. Aruwani ${ }^{6}$, Dua Khalid ${ }^{6}$, Haya Khalid ${ }^{6}$, Sidra Memon ${ }^{6}$

1. Internal Medicine, INTEC Education College, Shah Alam, MYS 2. Internal Medicine, Universidad Iberoamericana, Santo Domingo, DOM 3. Medicine, Liaquat University of Medical and Health Sciences, Jamshoro, PAK 4. Internal Medicine, Ghulam Muhammad Mahar Medical College, Sukkur, PAK 5. Internal Medicine, Shaheed Zulfiqar Ali Bhutto Medical University, Islamabad, PAK 6. Internal Medicine, Jinnah Sindh Medical University, Karachi, PAK

Corresponding author: Abdul Subhan Talpur, abdul_subhan17t@hotmail.com

\begin{abstract}
Introduction: Atherosclerosis contributes to the underlying pathophysiology for peripheral arterial disease (PAD), coronary artery disease (CAD), and cerebrovascular disease. Several studies have been conducted to demonstrate PAD as a major risk factor for cardiovascular (CV) events, however, the regional data are limited. This study aims to highlight PAD as a major risk factor in CV events in a local setting.

Methods: In this longitudinal study, 400 hypertensive patients with a confirmed diagnosis of PAD were enrolled from the outpatient department of the cardiology unit. Diagnosis of PAD was made using the ankle brachial index $(\mathrm{ABI})$. ABI less than 0.9 was labeled as participants with PAD. Another group of 400 without $\mathrm{PAD}$ was also enrolled as the control group from the outpatient department of cardiology unit. Patients were followed up for 12 months or for the development of myocardial infarction (MI).
\end{abstract}

Result: Participants with PAD had a significant increased risk of total MI events with a relative risk (RR) of 1.67 (confidence interval, CI 95\%: 1.05-2.66; p-value: 0.02). The RR for fatal MI was 2.62 (CI 95\%: 0.94-7.29; p-value: 0.06 ) compared to the participants without PAD, however, it was not significant.

Conclusion: This study has focused on the risk factors of PAD and has suggested that the patients who have any of the mentioned risk factors should be treated with caution under strict instructions given by doctors. A variety of treatment options is available, but the initial changes should be made in the lifestyle of these patients, making sure the risk factors are being treated.

Review began 05/24/2021 Review ended 06/02/2021 Published 06/15/2021

\section{() Copyright 2021}

Pérez Mejias et al. This is an open access article distributed under the terms of the Creative Commons Attribution License CC-BY 4.0., which permits unrestricted use, distribution, and reproduction in any medium, provided the original author and source are credited.
Categories: Cardiology, Internal Medicine

Keywords: peripheral artery disease, risk factor, myocardial infarction, association, fatal myocardial infarction

\section{Introduction}

Atherosclerosis contributes to the underlying pathophysiology for peripheral arterial disease (PAD), coronary artery disease (CAD), and cerebrovascular disease [1]. This condition is characterized by a diseased endothelium, low-grade inflammation, lipid accumulation, and plaque formation within the intima of the vessel wall [2]. Rupture of the plaque can provoke superimposed atherothrombosis as well as occlusion of the vessel wall, which leads to the development of cardiovascular (CV) events including myocardial infarction (MI), stroke, limb ischemia, and CV death [3]. Disease in more than one arterial bed is associated with the worst prognosis [4]. However, the prognosis can be improved through secondary preventive measures, with lifestyle changes and medicinal control of modifiable CV risk factors [5].

Several studies have been conducted to demonstrate PAD as a major risk factor for CV events. According to the 2016 study, the global burden of CV disease due to PAD was estimated to be $25.6 \%$ and $1.7 \%$ of the overall global burden of the disease [6]. Reduced quality of life (QOL) was predominantly associated with patients with PAD because of the functional limitations caused by the symptoms. In the European Union and the United States National Health and Wellness Survey, it was reported that patients with PAD had a lower mental and physical health-related QOL [7]. Major adverse CV events are associated with PAD. Blin et al. revealed that within a year of MI, PAD was the most important factor in predicting the risk of re-infarction, stroke, or transient ischemic attack [8].

This study aims to highlight PAD as a major risk factor in CV events. This further emphasizes the coping strategies and follows the secondary measures to improve the QOL in patients with PAD.

\section{Materials And Methods}

This longitudinal study was conducted from April 2019 to February 2021 in the cardiology unit of a tertiary care hospital. We enrolled 400 hypertensive patients with a confirmed diagnosis of PAD from the outpatient 


\section{Cureus}

department of cardiology via consecutive convenient non-probability sampling. Diagnosis of PAD was made using the ankle brachial index (ABI). ABI less than 0.9 was labeled as participants with PAD. Another set of 400 participants without PAD were also enrolled from the outpatient department as the control group.

The patient's characteristics such as age, gender, history of smoking, blood pressure, previous and family history for MI were noted in a self-structured questionnaire. Patients were followed up for 12 months or until the development of MI, whichever came first. MI was diagnosed based on symptoms, electrocardiogram (ECG), and cardiac enzymes.

Participants lost to follow-up in groups with and without PAD were 47 and 43, respectively. Only participants who completed the study were included in the final analysis. Statistical analysis was done using the Statistical Packages for Social Sciences (SPSS) version. 23.0 (IBM Corporation, Armonk, New York, USA). Continuous variables were analyzed via descriptive statistics and were presented as mean and standard deviation (SD) while categorical variables were presented as percentages and frequencies. Relative risk (RR) was calculated via an online calculator (MedCalc Software Ltd., Acacialaan 22, 8400 Ostend, Belgium) using a $95 \%$ confidence interval (CI). A p-value of less than 0.05 meant that there is a difference between the two groups and the null hypothesis is void.

\section{Results}

Seven hundred and ten (710) participants completed the study, 353 and 357 participants with and without the PAD group, respectively. There was no difference in demographics and the risk factor profile between the two groups (Table 1).

\begin{tabular}{|c|c|c|c|}
\hline Characteristics & Participants with PAD (n=353) & Participants without PAD ( $n=357$ ) & p-value \\
\hline Age in year (mean $\pm S D$ ) & $47 \pm 11$ & $48 \pm 10$ & 0.20 \\
\hline Male (\%) & 201 (56.9\%) & 198 (55.5\%) & 0.69 \\
\hline Smoking (\%) & $121(34.2 \%)$ & $127(35.5 \%)$ & 0.71 \\
\hline Diabetes (\%) & $178(50.4 \%)$ & $182(50.9 \%)$ & 0.88 \\
\hline Hypercholesterolemia & $213(60.3 \%)$ & $221(61.9 \%)$ & 0.66 \\
\hline BMI greater than $25 \mathrm{~kg} / \mathrm{m}^{2}(\%)$ & $98(27.7 \%)$ & $101(28.2 \%)$ & 0.87 \\
\hline Previous history of acute MI (\%) & $25(7.0 \%)$ & $17(4.7 \%)$ & 0.19 \\
\hline Family history of acute MI (\%) & $10(2.8 \%)$ & $12(3.3 \%)$ & 0.68 \\
\hline
\end{tabular}

\section{TABLE 1: Characteristics of the study participants.}

BMI, body mass index; MI, myocardial infarction; NS, non-significant; PAD, peripheral artery disease; SD, standard deviation

Participants with PAD had a significant increased risk of total MI events with a RR of 1.67 (CI 95\%: 1.052.66; p-value: 0.02). The RR for fatal MI was 2.62 (CI 95\%: 0.94-7.29; p-value: 0.06) compared to the participants without PAD, however, it was not significant (Table 2).

\begin{tabular}{|c|c|c|c|c|c|}
\hline MI & Participants with PAD (n=353) & Participants without PAD (n=357) & Relative risk (Cl 95\%) & NNH & p-value \\
\hline Total MI & $43(12.1 \%)$ & $26(7.2 \%)$ & $1.67(1.05-2.66)$ & 20.4 & 0.02 \\
\hline Non-fatal MI & $30(8.4 \%)$ & $22(6.1 \%)$ & $1.37(0.81-2.34)$ & 42.8 & 0.23 \\
\hline Fatal MI & $13(3.6 \%)$ & $4(1.1 \%)$ & $2.62(0.94-7.29)$ & 43.8 & 0.06 \\
\hline
\end{tabular}

TABLE 2: Classification of MI in participants with and without PAD.

$\mathrm{NNH}$, number needed to harm; MI, myocardial infarction; PAD, peripheral artery disease

\section{Discussion}


In our study, both groups did not show any significant differences in their demographics. Risk factors namely smoking, diabetes, hypercholesterolemia, BMI greater than $25 \mathrm{~kg} / \mathrm{m} 2$, previous and family history of acute MI did not vary significantly.

Our results demonstrated that patients with PAD were reported to be at a greater risk of total and fatal MI, compared to those who did not have PAD. However, the trends were not significant for fatal MI. This may be due to a limited number of fatal events. These results are supported by the fact that PAD is known to be a potential cause of cerebrovascular and CV episodes along with higher mortality rates [9-11]. PAD is known to be associated with acute MI [11-13]. Our results have been supported by other studies [14-18] that stated that $9 \%$ of acute MI had a prior history of PAD, and PAD was mostly reported among those at a higher risk of having underlying diseases like hypertension, diabetes, and stroke [14, 19-21].

The major risk factors for PAD are smoking, hypertension, hyperlipidemia, diabetes, obesity, and a family history of vascular disease. The National Health and Nutrition Examination Survey of 1999-2000 examined 2000 patients with PAD and concluded that approximately $95 \%$ of them had at least one of the mentioned risk factors, and up to $70 \%$ had more than two risk factors [22]. PAD patients who had diabetes and smoking habits were 2.5 times at an increased risk of morbidity and mortality [23]. Diabetes is known to be linked with accelerated atherosclerosis and increased episodes of cardiac events [24]. Novel risk factors include increased inflammatory markers such as C-reactive protein, fibrinogen, and plasma homocysteine [25]. Hyperhomocysteinemia is also an independent risk factor for PAD [26]. There are various strategies related to the treatment of PAD, including lifestyle modification, medical management, endovascular therapies, and surgical interventions. These strategies help in the management of claudication symptoms and secondary prevention of CV complications [27].

To the best of our knowledge, this is the first study from this South Asian region to study PAD as a risk factor for MI. However, since the study was conducted in a single center, care should be taken while inferring the result to a larger population. This study has focused on the risk factors of PAD and has suggested that the physician should treat the patients who have any of the mentioned risk factors with caution under strict instructions.

\section{Conclusions}

Peripheral arterial disease is known to potentially cause a global burden by leading to MI. However, our study is of the idea that by tracing the risk factors, PAD could be treated even before the onset of complications. Therefore, proper screening and safe treatment options could help in the long term. Moreover, to ensure the effectiveness of the treatment, check-ups should be done at regular intervals.

\section{Additional Information \\ Disclosures}

Human subjects: Consent was obtained or waived by all participants in this study. Liaquat University of Medical and Health Sciences issued approval LUMHS/IRB-Ofc/2019/02-04. Animal subjects: All authors have confirmed that this study did not involve animal subjects or tissue. Conflicts of interest: In compliance with the ICMJE uniform disclosure form, all authors declare the following: Payment/services info: All authors have declared that no financial support was received from any organization for the submitted work. Financial relationships: All authors have declared that they have no financial relationships at present or within the previous three years with any organizations that might have an interest in the submitted work. Other relationships: All authors have declared that there are no other relationships or activities that could appear to have influenced the submitted work.

\section{References}

1. Libby P: Mechanisms of acute coronary syndromes and their implications for therapy . N Engl J Med. 2013, 368:2004-2013. 10.1056/NEJMra1216063

2. Libby P, Ridker PM, Hansson GK: Progress and challenges in translating the biology of atherosclerosis . Nature. 2011, 473:317-325. 10.1038/nature10146

3. Bauersachs R, Zannad F: Rivaroxaban: a new treatment paradigm in the setting of vascular protection? . Thromb Haemost. 2018, 118:S12-S22. 10.1055/s-0038-1636530

4. Steg PG, Bhatt DL, Wilson PW, et al.: One-year cardiovascular event rates in outpatients with atherothrombosis. JAMA. 2007, 297:1197-1206. 10.1001/jama.297.11.1197

5. Cortés-Beringola A, Fitzsimons D, Pelliccia A, Moreno G, Martín-Asenjo R, Bueno H: Planning secondary prevention: room for improvement. Eur J Prev Cardiol. 2017, 24:22-28. 10.1177/2047487317704954

6. GBD 2016 Disease and Injury Incidence and Prevalence Collaborators: Global, regional, and national incidence, prevalence, and years lived with disability for 328 diseases and injuries for 195 countries, 19902016: a systematic analysis for the Global Burden of Disease Study 2016. Lancet. 2017, 390:1211-1259. 10.1016/S0140-6736(17)32154-2

7. Marrett E, DiBonaventura Md, Zhang Q: Burden of peripheral arterial disease in Europe and the United States: a patient survey. Health Qual Life Outcomes. 2013, 11:175. 10.1186/1477-7525-11-175

8. Blin P, Philippe F, Bouée S, et al.: Outcomes following acute hospitalised myocardial infarction in France: an insurance claims database analysis. Int J Cardiol. 2016, 219:387-393. 10.1016/j.ijcard.2016.06.102 
9. Alzamora MT, Forés R, Baena-Díez JM, et al.: The peripheral arterial disease study (PERART/ARTPER): prevalence and risk factors in the general population. BMC Public Health. 2010, 10:38. 10.1186/1471-245810-38

10. Diehm C, Schuster A, Allenberg JR, et al.: High prevalence of peripheral arterial disease and co-morbidity in 6880 primary care patients: cross-sectional study. Atherosclerosis. 2004, 172:95-105. 10.1016/s00219150(03)00204-1

11. Mehlsen J, Wiinberg N, Joergensen BS, Schultz-Larsen P: High prevalence of peripheral arterial disease in patients with previous cerebrovascular or coronary event. Blood Press. 2010, 19:308-312. 10.3109/08037051.2010.491178

12. Perk J, De Backer G, Gohlke H, et al.: European Guidelines on cardiovascular disease prevention in clinical practice (version 2012): The Fifth Joint Task Force of the European Society of Cardiology and Other Societies on Cardiovascular Disease Prevention in Clinical Practice (constituted by representatives of nine societies and by invited experts). Atherosclerosis. 2012, 223:1-68. 10.1016/j.atherosclerosis.2012.05.007

13. Reiner Z, Catapano AL, De Backer G, et al.: ESC/EAS Guidelines for the management of dyslipidaemias: the Task Force for the management of dyslipidaemias of the European Society of Cardiology (ESC) and the European Atherosclerosis Society (EAS). Eur Heart J. 2011, 32:1769-1818. 10.1093/eurheartj/ehr158

14. Inglis SC, Bebchuk J, Al-Suhaim SA, et al.: Peripheral artery disease and outcomes after myocardial infarction: an individual-patient meta-analysis of 28,771 patients in CAPRICORN, EPEHESUS, OPTIMAAL and VALIANT. Int J Cardiol. 2013, 168:1094-1101. 10.1016/j.ijcard.2012.11.033

15. Froehlich JB, Mukherjee D, Avezum A, et al.: Association of peripheral artery disease with treatment and outcomes in acute coronary syndromes. The Global Registry of Acute Coronary Events (GRACE). Am Heart J. 2006, 151:1123-1128. 10.1016/j.ahj.2005.11.005

16. Saw J, Bhatt DL, Moliterno DJ, et al.: The influence of peripheral arterial disease on outcomes: a pooled analysis of mortality in eight large randomized percutaneous coronary intervention trials. J Am Coll Cardiol. 2006, 48:1567-1572. 10.1016/j.jacc.2006.03.067

17. Bhatt DL, Peterson ED, Harrington RA, et al.: Prior polyvascular disease: risk factor for adverse ischaemic outcomes in acute coronary syndromes. Eur Heart J. 2009, 30:1195-1202. 10.1093/eurheartj/ehp099

18. Kirchberger I, Amann U, Heier M, Kuch B, Thilo C, Peters A, Meisinger C: Presenting symptoms, pre-hospital delay time and 28-day case fatality in patients with peripheral arterial disease and acute myocardial infarction from the MONICA/KORA Myocardial Infarction Registry. Eur J Prev Cardiol. 2017, 24:265-273. $10.1177 / 2047487316676123$

19. Al-Thani HA, El-Menyar A, Zubaid M, et al.: Peripheral arterial disease in patients presenting with acute coronary syndrome in six middle eastern countries. Int J Vasc Med. 2011, 2011:815902. 10.1155/2011/815902

20. Guerrero M, Harjai K, Stone GW, et al.: Usefulness of the presence of peripheral vascular disease in predicting mortality in acute myocardial infarction patients treated with primary angioplasty (from the Primary Angioplasty in Myocardial Infarction Database). Am J Cardiol. 2005, 96:649-654. 10.1016/j.amjcard.2005.04.037

21. Patel MR, Becker RC, Wojdyla DM, et al.: Cardiovascular events in acute coronary syndrome patients with peripheral arterial disease treated with ticagrelor compared with clopidogrel: data from the PLATO Trial. Eur J Prev Cardiol. 2015, 22:734-742. 10.1177/2047487314533215

22. Selvin E, Erlinger TP: Prevalence of and risk factors for peripheral arterial disease in the United States: results from the National Health and Nutrition Examination Survey, 1999-2000. Circulation. 2004, 110:738743. 10.1161/01.CIR.0000137913.26087.F0

23. Lu L, Mackay DF, Pell JP: Meta-analysis of the association between cigarette smoking and peripheral arterial disease. Heart. 2014, 100:414-423. 10.1136/heartjnl-2013-304082

24. Selvin E, Marinopoulos S, Berkenblit G, Rami T, Brancati FL, Powe NR, Golden SH: Meta-analysis: glycosylated hemoglobin and cardiovascular disease in diabetes mellitus. Ann Intern Med. 2004, 141:421431. 10.7326/0003-4819-141-6-200409210-00007

25. Ridker PM, Stampfer MJ, Rifai N: Novel risk factors for systemic atherosclerosis: a comparison of C-reactive protein, fibrinogen, homocysteine, lipoprotein(a), and standard cholesterol screening as predictors of peripheral arterial disease. JAMA. 2001, 285:2481-2485. 10.1001/jama.285.19.2481

26. Smith SC Jr, Milani RV, Arnett DK, et al.: Atherosclerotic vascular disease conference: writing group II: risk factors. Circulation. 2004, 109:2613-2616. 10.1161/01.CIR.0000128519.60762.84

27. Bevan GH, White Solaru KT: Evidence-based medical management of peripheral artery disease . Arterioscler Thromb Vasc Biol. 2020, 40:541-553. 10.1161/ATVBAHA.119.312142 